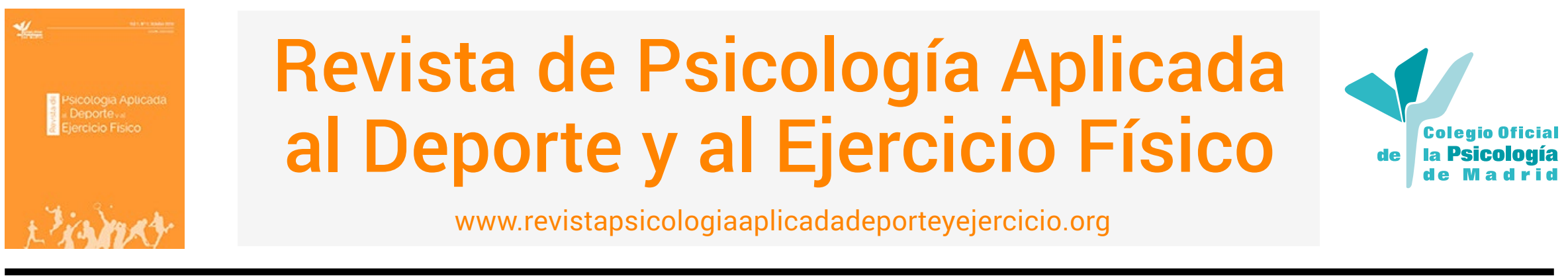

\title{
Aplicación del modelo "Cadena de conciencia" y efectos sobre la orientación motivacional y la confianza
}

\author{
Núria Rabassa \\ Valor positiu, Vilablareix, España
}

\author{
Joan Vives-Ribó \\ Departamento de Psicología del Deporte, Centro de Alto Rendimiento (CAR), España
}

RESUMEN: 'La Cadena de la Conciencia' (Vives, 2011) es un modelo de intervención sobre la comunicación del entrenador. Para estudiar los efectos indirectos en deportistas, se trabajó con dos equipos juveniles de baloncesto, aplicando el modelo en el grupo experimental y comparando con el grupo control las variables evaluadas pre-pos intervención: estilo comunicativo de entrenadores (cuestionario ad hoc), y orientación motivacional y confianza rasgo de jugadores (COI y TSCl; Vealey, 1986). Los resultados indican que el entrenador del grupo experimental mejora en todas las fases comunicativas del modelo, y sus jugadoras aumentan la orientación motivacional a la tarea y la confianza, y disminuyen la orientación al ego. Todos los cambios son significativos en el grupo experimental y muestran mayor magnitud de efecto que en el grupo control. Se concluye que la aplicación efectiva de las indicaciones comunicativas del modelo incide positivamente en la confianza y la orientación motivacional de los deportistas.

PALABRAS CLAVES: Comunicación, aprendizaje consciente, clima motivacional, motivación de logro, autoeficacia, baloncesto.

\section{Application of the "Chain of consciousness" model and effects on motivational orientation and confidence}

ABSTRACT: 'The Chain of Consciousness' (Vives, 2011) is a model of intervention on coach communication. To study the indirect effects in athletes, we worked with two youth basketball teams, applying the model in the experimental group and comparing the variables evaluated before and after the intervention against a control group: communicative style of coaches (ad hoc questionnaire), and motivational orientation and trait-confidence of the players (COI and TSCl; Vealey, 1986). The results indicated that the coach of the experimental group improved in all the communicative phases proposed by the model, and his players increased their motivational orientation to the task and confidence, and decreased their ego-orientation. All changes were significant in the experimental group and showed a greater effect size than the control group. It is concluded that the effective application of the communicative indications of the model positively affects the confidence and motivational orientation of athletes.

KEYWORDS: Communication, conscious learning, motivational climate, achievement motivation, self-efficacy, basketball.

\section{Aplicação do modelo "Cadeia de consciência" e efeitos na orientação motivacional e confiança}

RESUMO: "A Cadeia de Consciência" (Vives, 2011) é um modelo de intervenção sobre a comunicação do treinador. Para estudar os efeitos indiretos em atletas, trabalhamos com duas equipas de basquetebol juvenil, aplicando o modelo no grupo experimental e comparando com o grupo de controlo as diferenças nas variáveis avaliadas pré-pós intervenção: estilo comunicativo dos treinadores (questionário ad hoc), e orientação motivacional e traço de confiança dos jogadores (COI e TSCl; Vealey, 1986). Os resultados indicam que o treinador do

\footnotetext{
Núria Rabassa iD https://orcid.org/0000-0002-2655-252X es psicóloga del deporte y el rendimiento en Valor Positiu.

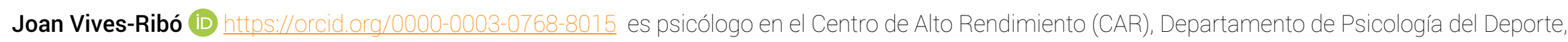
Sant Cugat del Vallès (Barcelona, España).

La correspondencia sobre este artículo debe enviarse a: Núria Rabassa. Valor Positiu. Carrer del Mas Falgàs, 2, 17180 Vilablareix (Girona, España). E-mail:
} rabassa230mail.com 
grupo experimental melhora em todas as fases comunicativas do modelo, e as suas jogadoras contribuem para o aumento da orientação motivacional para a tarefa e a confiança, e contribuem para a diminuição da orientação para o ego. Todas as mudanças são significativas no grupo experimental e mostram uma magnitude de efeito maior do que no grupo de controlo. Conclui-se que a aplicação efetiva das indicações comunicativas do modelo afeta positivamente a confiança e a orientação motivacional dos atletas.

PALAVRAS-CHAVE: Comunicação, aprendizagem consciente, clima motivacional, motivação de realização, autoeficácia, basquetebol.

Artículo recibido: 05/02/2021 | Artículo aceptado: 30/05/2021

El papel y la influencia del entrenador sobre el clima y la orientación motivacional han sido extensamente estudiados, especialmente en deportes de equipo (Cordo-Cabal et al., 2019; Reigal et al., 2018; Balaguer et al.. 2011; Cruz et al., 2010; Almagro et al., 2009; Smith et al., 2009; Torregrossa et al., 2008). En Smith y Smoll (2017) se repasa la aportación del modelo teórico mediacional, el cual estipula que los comportamientos del entrenador están mediatizados por el significado que los deportistas les confieren a partir de sus percepciones y recuerdos. A partir de este modelo se desarrolló el Coaching Behavior Assessment System (CBAS) como herramienta de observación, con el objetivo de evaluar e identificar las conductas emitidas por los entrenadores. De la investigación desarrollada con él, surgieron las pautas de entrenamiento que en 1979 formaron la base del programa de intervención Coach Effectiveness Training (CET) y más adelante, el Mastery Approach to Coaching (MAC; Smoll, et al., 2007), que ya incluye los postulados de la teoría de motivación de logro. Esta teoría plantea que según el clima motivacional (enfocado a la maestría y al disfrute o bien a los resultados y a sus consecuencias) pueden generarse dos concepciones del éxito (orientada a la tarea, con una concepción del éxito auto-referenciada, o bien orientada al ego, con una concepción del éxito vinculada a la comparación con otros). Tradicionalmente, los programas CET / MAC se ofrecen en formato de taller, pero Sousa et al. (2015) indican que el reducido número de horas de intervención directa no es suficiente para producir cambios en un corto espacio de tiempo para que, además, se mantengan a lo largo del tiempo.

Muchos psicólogos deportivos acaban trabajando con los entrenadores de forma individual. Morgan (2017) expone la importancia de trabajar con los entrenadores con el fin de promocionar el uso de herramientas comunicativas para fomentar un clima motivacional orientado a la tarea, proporcionar más feedback positivo que negativo, premiar el esfuerzo y la superación personal, y evitar las comparaciones entre deportistas. En este sentido, el Grup d'Estudis de Psicologia de l'Esport (GEPE) elaboró los Programas de Asesoramiento Personalizado a Entrenadores (PAPE), con sesiones individualizadas, para hacerles tomar conciencia de sus comportamientos y analizar las conductas a mantener o a disminuir (Sousa et al., 2006; Sousa et al., 2008; Rodríguez et al., 2017). En el entorno de este grupo de estudios, vinculado a la Universitat Autònoma de Barcelona (UAB), se han realizado numerosos trabajos con una estructura procedimental similar entre ellos, basada en estas fases: 1/ establecimiento de línea base descriptiva del comportamiento del entrenador gracias a observación realizada con el CBAS; 2/ intervención a partir de instrucciones didácticas basadas en el CET, feedback conductual al entrenador, establecimiento de objetivos elegidos por el propio entrenador, y role-playing de las conductas objetivo; y 3 / evaluación de la intervención. La mayoría de trabajos constatan cambios a favor de conseguir un clima de implicación a la tarea, más apoyo y menos punición. Estos cambios son especialmente perceptibles en aquellos objetivos auto-elegidos por el entrenador, si bien también se observan cambios en otras áreas de conducta, debido a los efectos transferidos por cambios en comportamientos clave (Cruz et al., 2016; Sousa et al., 2006; Sousa et al., 2008).

Rodríguez et al. (2017) plantearon una estructura con algunas similitudes al intentar demostrar que en los ambientes en los que se fomenta el aprendizaje, la mejora personal y la participación, hay más susceptibilidad de generar climas motivacionales hacia la tarea. Pero en su caso, al intervenir con los entrenadores (4, de 4 clubes diferentes), utilizaron las pautas del programa que Ames (1992) diseñó para fomentar climas motivacionales de implicación hacia la tarea, basado en seis dimensiones o estructuras del entorno de aprendizaje, identificadas con el acrónimo TARGET: (T) Tarea; (A) Autoridad o forma de liderar; (R) Reconocimiento o formas de motivar; (G) Agrupación o distribución de tareas y deportistas; (E) Evaluación o forma de dar feedback, supervisar y valorar los objetivos, o fomentar la autoevaluación; y, (T) Tiempo para llevar a cabo las tareas. Sus resultados mostraron que, a pesar de obtenerse algunos cambios conductuales en la dirección esperada, la implicación a la tarea no aumentó según lo planteado. En cambio, aplicando también una metodología 
basada en estas dimensiones, Álvarez et al. (2013) sí obtuvieron resultados favorables en su intervención con un equipo de gimnasia rítmica, consiguiendo una disminución del clima de implicación al ego y aumentando la orientación a la tarea.

Otro enfoque teórico relevante en el estudio de los efectos de las conductas de los entrenadores sobre la motivación de los deportistas es la teoría de la auto-determinación, que incide en la satisfacción de las tres necesidades psicológicas básicas (autonomía, competencia y relación) para conseguir una participación más intrínsecamente motivada y saludable (Deci y Ryan, 2012). Como ejemplo aplicado de este enfoque, cabe destacar el proyecto europeo Empowering Coaching ${ }^{\mathrm{TM}}$ (Duda, 2013), que comparte principios con la teoría de motivación de logro. Este programa forma a entrenadores durante 6 horas, a través de sesiones interactivas y de auto-reflexión, dándoles pautas para generar climas empowering, que se caracterizan por una alta implicación en la tarea (e.g., maestría en la tarea, aprendizaje, esfuerzo, claridad de rol en el equipo, cooperación), un alto apoyo a la autonomía (e.g., apoyo, flexibilidad, motivación a través del interés, participación en las decisiones) y un alto apoyo social (e.g., atmósfera de comprensión y confianza; Castillo et al., 2015).

Pulido et al. (2019) diseñaron un programa de formación de entrenadores en el cual utilizaron como instrumento de evaluación el Coach Interpersonal Style Observational System (CISOS). Este programa se basa también en las premisas de la teoría de la autodeterminación, a través del cual fomentan estrategias motivacionales y metodológicas para optimizar las necesidades psicológicas básicas de autonomía, competencia y relaciones sociales de los deportistas, aumentando las conductas de apoyo al aprendizaje, y reduciendo las conductas asociadas a un estilo interpersonal controlador. En su trabajo con 8 entrenadores, no obtuvieron diferencias significativas entre grupos, aunque los resultados del grupo experimental demostraron una tendencia positiva entre las medidas pre y pos intervención. Aun así, abogan por incrementar el tiempo de impartición del programa y reforzarlo con una supervisión reflexiva por parte de expertos.

Muchos psicólogos del deporte aplicados consideran el aumento de la confianza como uno de los objetivos principales de las intervenciones con deportistas. En deportes de equipo, este objetivo puede ser abordado de forma eficaz y eficiente a través de la intervención con el entrenador, empoderándole para aprovechar la gestión psicológica que él pueda llevar a cabo en las dinámicas de entrenamiento y competición, teniendo en cuenta su ascendencia con los deportistas (Peris y Cantón, 2018; Villalonga et al., 2015).
Para poder realizar una intervención psicológica a través del entrenador que sea efectiva, es importante poder vincular todo el background relativo a la intervención sobre la influencia del entrenador en el clima y la orientación motivacional de los deportistas, con los efectos en las variables psicológicas que más influencia pueden tener en el rendimiento. Harwood (2008), en su programa de intervención para entrenadores $(5 \mathrm{C})$, plantea la confianza, juntamente con el compromiso, la comunicación, la concentración y el control, como atributos clave para el ajuste, la motivación y la interrelación con los deportistas. Machida et al. (2012), siguiendo el enfoque conceptual más estudiado para la confianza en el deporte (Sport Confidence Model; Vealey, 1986), identificaron la orientación y el clima motivacional hacia la tarea como fuentes controlables de importancia crítica para la confianza. Crear un ambiente positivo y acogedor, responder a los deportistas de manera productiva, desarrollar prácticas efectivas para el entrenamiento, desarrollar relaciones interpersonales con los deportistas y poseer cualidades intrapersonales efectivas, son conductas identificadas como importantes para desarrollar la confianza en los deportistas (Forlenza et al., 2018).

Reigal et al. (2018) estudiaron las percepciones del deportista sobre el clima motivacional generado por sus entrenadores y la asociación con sus habilidades psicológicas. Encontraron que existe una relación positiva muy significativa entre el clima de apoyo a la autonomía y el clima orientado a la tarea con la autoconfianza en jugadores de balonmano playa. Más recientemente, Pineda-Espejel et al. (2020) han puesto a prueba un modelo teórico que examina la siguiente secuencia: estilo interpersonal del entrenador percibido por los deportistas, necesidad de competencia, regulaciones motivacionales y consecuencias de autoconfianza y ansiedad precompetitivas. Han encontrado que el estilo de apoyo a la autonomía por parte del entrenador predice positivamente la satisfacción de competencia, y, en consecuencia, la motivación autónoma hacia la participación deportiva, y la autoconfianza precompetitiva.

Desde la práctica aplicada, Vives (2011) presenta un modelo de intervención con el entrenador denominado "La cadena de la conciencia" (CC), que incide especialmente en la comunicación instructiva para potenciar el aprendizaje consciente de los deportistas (denominado aprendizaje explícito por Latinjak, 2014), y de esta manera, favorecer la confianza a partir de las creencias generadas por los recursos técnico-tácticos aprendidos, y en consecuencia, incrementar la autoeficacia en el momento de aplicar dichos recursos ante una tarea o en competición. Vives-Ribó y Rabassa (2020) desarrollan las indicaciones comunicativas que ofrece el modelo en torno a una estructura co- 
municativa replicable para cada ejercicio a realizar en el entrenamiento, denominada Patrón Comunicativo Replicable (PCR), y que consta de cuatro fases: 1/ planteamiento de objetivos, 2/ instrucciones acerca de la concentración $3 /$ correcciones y 4 / feedback final. Aplicaron este modelo como metodología principal para intervenir en un equipo de hockey hierba profesional en crisis de resultados, con el objetivo de orientar al equipo hacia la tarea y recuperar la confianza de las jugadoras, y así conseguir la estabilidad emocional y la concentración adecuadas para afrontar lo mejor posible la competición. Se consiguieron resultados deportivos muy positivos ( 6 victorias en 6 partidos), aunque no se pudieron evaluar las variables implicadas, ni por lo tanto someter los cambios percibidos a contraste estadístico.

Con el presente trabajo, se pretende contribuir dando inicio al estudio de la validez de este modelo, proveniente de la práctica aplicada, y que se distingue por proponer el aprendizaje consciente de los deportistas como variable dependiente de la comunicación del entrenador, y a la vez, como variable precursora sobre los efectos en la orientación motivacional y la confianza de los deportistas. El objetivo específico de este trabajo es contrastar la relación que pueda haber entre la aplicación del modelo CC y los efectos esperados sobre la orientación motivacional y la confianza de los deportistas. Se defiende la hipótesis que, en caso de producirse cambios comunicativos en el sentido marcado por el modelo, estos incidirán positivamente en la orientación hacia la tarea y los niveles de confianza.

\section{Método}

\section{Participantes}

Dos equipos de baloncesto de categoría junior (nivel A), masculino y femenino, de un mismo club. El grupo de jugadoras del equipo femenino ( $n=10 ; M=16.5 ; D \cdot T=.53)$ y su entrenador (25 años) fueron escogidos al azar como grupo experimental (GE). Los jugadores del equipo masculino ( $n$ $=10 ; M=16.3 ; D \cdot T=.48$ ) y su entrenador (29 años), como grupo control (GC). Ambos entrenadores, contaban con la titulación federativa de Nivel 1 (de 3).

Ambos equipos realizaban tres sesiones de entrenamiento a la semana: lunes, miércoles y viernes; de 19:30 h. a 20:30 h. (masculino), y de 20:30 h. a 21:30 h. (femenino).

Los autores que realizaron la intervención, la observación y registro, y la evaluación previa y posterior, son ambos licenciados en Psicología, con formación de tercer grado especializada en Psicología del Deporte, y con 5 y 18 años de experiencia aplicada, respectivamente, en el momento de la intervención.

\section{Instrumentos}

Cuestionario sobre el Estilo Comunicativo del Entrenador, creado ad hoc, en el que los 18 ítems son las propias indicaciones comunicativas del modelo CC, sustentadas por un amplio background teórico, descrito en Vives-Ribó y Rabassa (2020). Pueden consultarse las indicaciones en la Tabla 2. Se responde según el seguimiento habitual (sí, a veces, no) de las indicaciones comunicativas por parte del entrenador. El cuestionario devuelve una puntuación de 0 a 10 según el seguimiento de las indicaciones comunicativas en cada fase del Patrón Comunicativo Replicable (PCR).

Auto-registro para el entrenador del GE, creado ad hoc, para valorar el seguimiento de cada indicación comunicativa del modelo (las mismas que en el cuestionario) durante el entrenamiento (sí, a veces, no). Se asignan valores numéricos a esta escala para poder sumar los valores conseguidos por cada indicación comunicativa y agruparlas por fases comunicativas del PCR, devolviendo una puntuación de 0 a 10 para cada fase (Objetivos, Concentración, Corrección, Feedback final).

Registro para las jugadoras del GE, creado ad hoc, con cuatro ítems referentes a las fases comunicativas del PCR (claridad en los objetivos, sensación de saber orientar la concentración, aprovechamiento de las correcciones y nivel de conciencia sobre los aprendizajes adquiridos), para valorar (de 0-10) la comunicación del entrenador.

Versión española del Trait Sport Confidence Inventory (TSCl; Vealey, 1986), traducida y adaptada por Herrera-Velásquez y Gómez-Maquet (2020), para evaluar el nivel de confianza rasgo de los jugadores. La raíz "Compara la confianza que tienes en ti mismo en tu habilidad para..." es común para los 13 ítems, a los que los deportistas deben responder con una escala Likert de 1 a 9 según su grado de confianza para diferentes recursos técnico-tácticos, la gestión psicológica y las posibilidades de éxito en los resultados. El cuestionario devuelve puntuación de 0 a 1 según el grado de confianza rasgo. Consistencia interna (alpha de Cronbach) de .93 y fiabilidad test-retest de $r=.86$.

Competitive Orientation Inventory (COI; Vealey, 1986), para evaluar la orientación motivacional de los jugadores (hacia el resultado o ego, o hacia el rendimiento o la tarea). No hay versiones traducidas de este cuestionario porque no contiene ítems. Se responde puntuando entre 0 y 10 (según el grado de satisfacción) cada una de las 16 celdas de una 
rejilla de $4 \times 4$, correspondientes a las situaciones hipotéticas que salen de la interacción entre resultado competitivo (ganar fácil o ajustado, perder ajustado o fácil) y rendimiento individual (muy bueno, bueno, malo, muy malo). El cuestionario devuelve puntuaciones de 0-100 para ambas orientaciones motivacionales. Fiabilidad test-retest de $r=$ .69 en orientación al rendimiento y $r=.67$ en orientación a resultados.

\section{Procedimiento}

Se realizó una sesión inicial para cada equipo, con entrenadores y deportistas, en la que se presentó la propuesta de estudio, se fijaron los acuerdos de colaboración (participación voluntaria y anónima), se explicó el uso y la confidencialidad de los datos recogidos, y se entregó el consentimiento informado de participación para los entrenadores y los tutores de los deportistas (menores de edad). Posteriormente, de forma colectiva, se administraron a ambos equipos (GE y GC, por separado) los cuestionarios para la evaluación previa a la intervención: Estilo Comunicativo del Entrenador, para entrenadores y jugadores; COI y TSCI solo para los jugadores.

En una segunda sesión (90'), los autores explicaron al entrenador del GE el modelo CC (Vives-Ribó y Rabassa, 2020) y le formaron en las indicaciones comunicativas del PCR, que luego debía aplicar en los entrenamientos (pueden consultarse las indicaciones en la Tabla 2).

La recogida de datos se inició en el entrenamiento posterior a la sesión formativa. En ese entrenamiento se les explicó a los componentes del GE (entrenador y jugadoras) cómo completar los registros y enviar la información numérica a la autora, a través del móvil, al finalizar cada entrenamiento.

Las 8 primeras semanas se estipularon como período de adiestramiento. Durante ese período, al menos uno de los autores estaba presente como mínimo en uno de los tres entrenamientos semanales del equipo femenino (grupo experimental), para dar feedback al entrenador en relación con el seguimiento de las pautas comunicativas y resolver cualquier duda que pudiese surgir.

Al finalizar este período de adiestramiento, se realizó otra sesión (90') con el entrenador del GE para hacer una valoración de la evolución y los cambios comunicativos observados hasta el momento, reforzando los progresos y repasando las indicaciones menos seguidas.

A partir de aquí se siguió con la aplicación del modelo durante 13 semanas más hasta finalizar el período competitivo. Durante estas semanas se mantuvo la presencia de uno de los autores en un entrenamiento por semana, que se aprovechaba para realizar in situ asesoramiento o feedback en relación con el seguimiento de las indicaciones comunicativas por parte del entrenador.

Al finalizar el período de intervención, se programó una sesión de evaluación final, en la que se administraron de nuevo a ambos equipos los mismos cuestionarios que en la evaluación inicial. Con el GC solo se tuvo contacto en dichas sesiones de evaluación.

Finalmente, se programó una última sesión con el entrenador del GE para hacer la devolución de los resultados de la intervención, reforzando los cambios comunicativos realizados, revisando los aspectos que más habían costado de aplicar, y comentando los resultados en relación con las variables evaluadas en las jugadoras.

\section{Análisis de datos}

Se utilizó el programa SPSS 17.0 para Windows. El análisis del efecto de la intervención sobre las variables objeto de estudio se llevó a cabo con un contraste no paramétrico (Wilcoxon) por tratarse de pocos sujetos y al no estar verificado que hubiese una distribución normal. También se calculó la magnitud del efecto con el índice $d$ de Cohen, considerándose, en valores absolutos, una magnitud de efecto leve a partir de .2, magnitud moderada a partir de .5, y magnitud elevada a partir de .8. (Fritz, et al., 2012).

\section{Resultados}

\section{Comparación de la conducta comunicativa antes y después de la intervención}

Las puntuaciones del Cuestionario sobre el Estilo Comunicativo del Entrenador recogidas por los propios entrenadores (Figura 1), muestran cambios pre-pos percibidos positivos y más visibles en el entrenador del GE. El entrenador del GC reporta puntuaciones menores en las medidas pos-intervención para todas las fases comunicativas, excepto en la Fase 2, correspondiente a dar las instrucciones.

Las diferencias entre puntuaciones medias dadas por los jugadores de ambos grupos (Tabla 1) para ese mismo cuestionario, muestran una evolución positiva en ambos grupos y en todas las fases comunicativas, aunque las diferencias son mayores y significativas (Wilcoxon, $\mathrm{p}<.05$ ) en el GE, para todas las fases, mientras que en el GC no lo fueron en la fase de Planteamiento objetivos ( .19) ni en Feedback final (.08). 
Figura 1. Diferencias pre-pos en las puntuaciones dadas por los entrenadores en el Cuestionario de Estilo Comunicativo

Estilo Comunicativo Entrenador

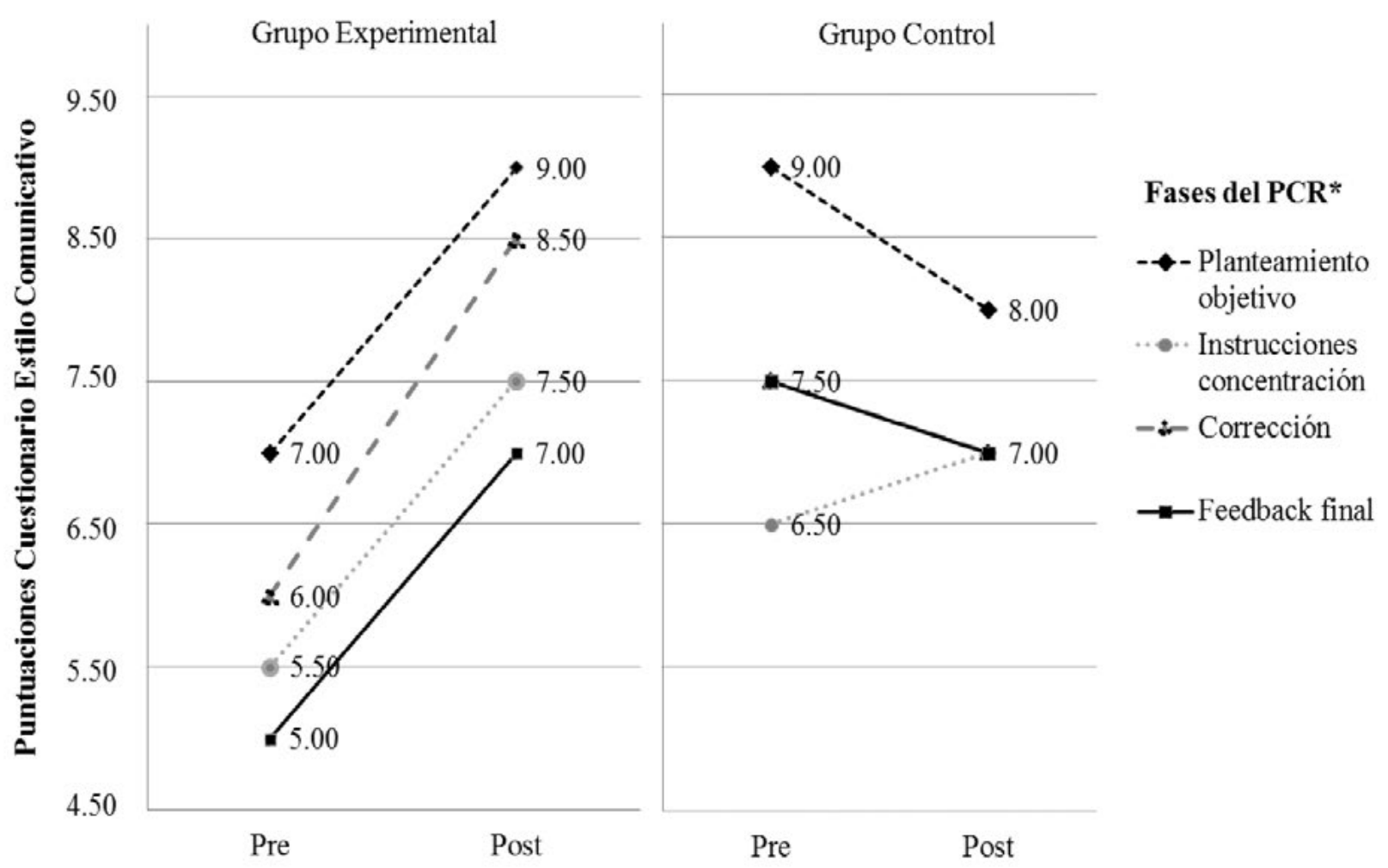

* PCR: Patrón Comunicativo Replicable del modelo La Cadena de la Conciencia

Tabla 1. Significación (Wilcoxon) de las diferencias pre-pos en el Cuestionario sobre el Estilo Comunicativo del Entrenador respondido por los jugadores

\begin{tabular}{|c|c|c|c|c|c|c|c|c|c|c|c|c|c|}
\hline \multicolumn{2}{|c|}{ Fases del PCR } & \multicolumn{3}{|c|}{ Planteamiento de objetivos } & \multicolumn{3}{|c|}{$\begin{array}{l}\text { Instrucciones para la } \\
\text { concentración }\end{array}$} & \multicolumn{2}{|c|}{ Correcciones } & \multicolumn{4}{|c|}{ Feedback final } \\
\hline & & M & Z & $\mathrm{p}$ & M & Z & $\mathrm{p}$ & M & Z & $\mathrm{p}$ & M & Z & $\mathrm{p}$ \\
\hline \multirow{2}{*}{ GE } & Pre & 6.8 & \multirow{2}{*}{-2.717} & \multirow{2}{*}{.007} & 5.9 & \multirow{2}{*}{-2.604} & \multirow{2}{*}{.009} & 6.80 & \multirow{2}{*}{-2.388} & \multirow{2}{*}{.017} & 4.75 & \multirow{2}{*}{-2.431} & \multirow{2}{*}{.015} \\
\hline & Pos & 9.22 & & & 8 & & & 7.72 & & & 7.5 & & \\
\hline \multirow{2}{*}{ GC } & Pre & 6.2 & \multirow{2}{*}{-1.289} & \multirow{2}{*}{.197} & 4.4 & \multirow{2}{*}{-2.558} & \multirow{2}{*}{.011} & 5.45 & \multirow{2}{*}{-2.214} & \multirow{2}{*}{.027. } & 3.8 & \multirow{2}{*}{-1.709} & \multirow{2}{*}{.088} \\
\hline & Pos & 6.7 & & & 5.2 & & & 6.15 & & & 4.8 & & \\
\hline
\end{tabular}

GE: Grupo experimental; GC: grupo control; M: Medias; Z: Wilcoxon pos-pre; p: Significación (p<.05).

La magnitud de efecto, calculada con la $d$ de Cohen, se muestra en la Figura 2. Los cambios percibidos en el GE son de mayor magnitud en todos los casos, especialmente elevada ( $>.08$ en valores absolutos) para las fases de Planteamiento objetivos (-1.95), Instrucciones para la concentración (-1.38) y Feedback final (-1.33).

\section{Progreso en la conducta comunicativa del entrenador (GE)}

La evolución de la conducta comunicativa del entrenador del GE, registrada a lo largo de 21 semanas, muestra una tendencia global positiva. En la evolución percibida por las jugadoras, diferenciada por fases comunicativas del PCR (Figura 3), la fase de Feedback final es la menos puntuada al principio, si bien a partir de la cuarta semana se ajusta a la tendencia de las puntuaciones recibidas en las otras fases. 
Figura 2. Magnitud de efecto para las diferencias pos-pre en los cambios comunicativos percibidos por los jugadores para cada fase comunicativa del Patrón Comunicativo Replicable

\section{Magnitud de los cambios comunicativos percibidos}

Fases comunicativas del Patrón Comunicativo Replicable

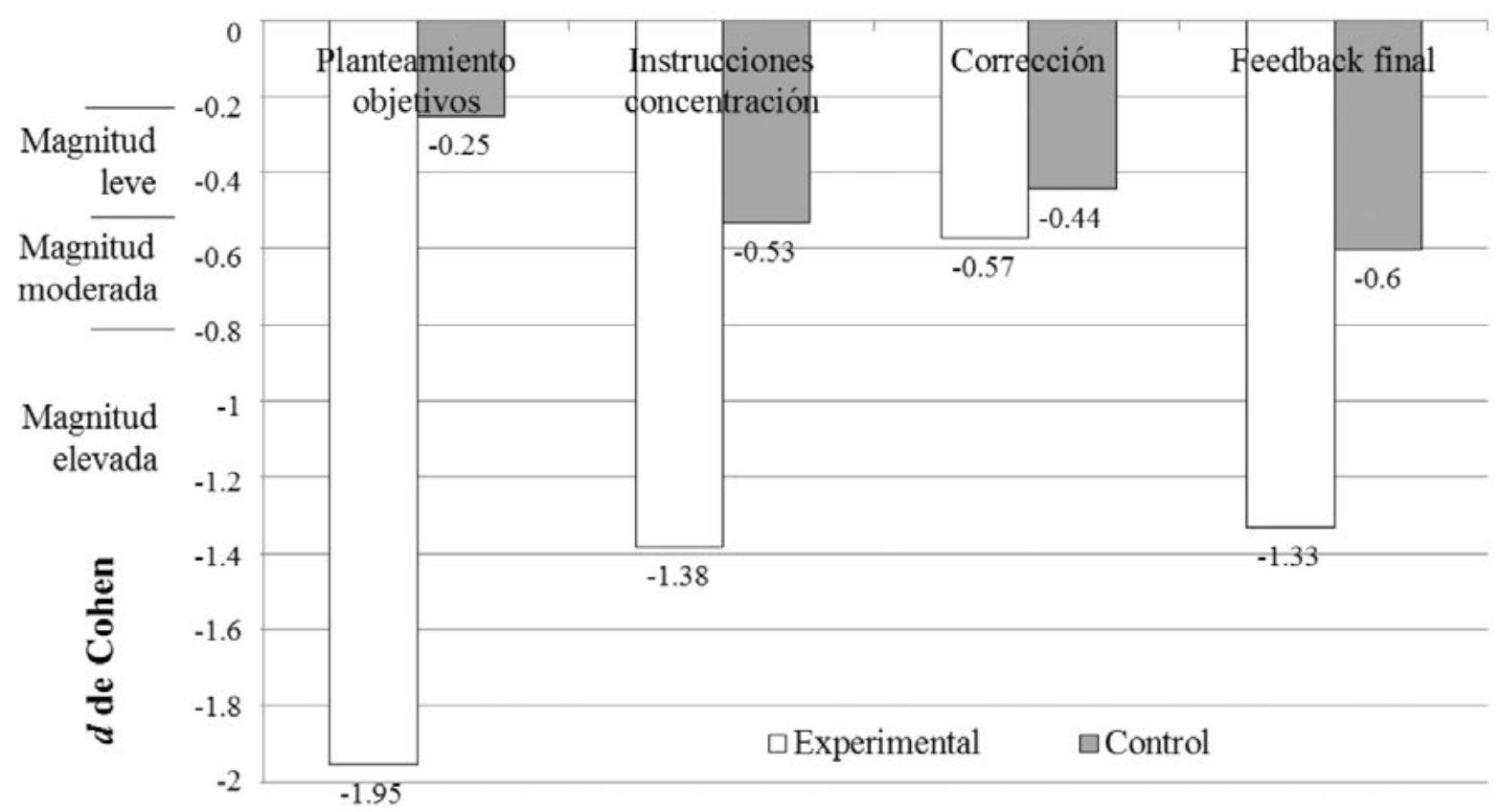

Nota: los valores $d$ negativos significan magnitud de efecto positivo. En términos absolutos, valores cercanos a 0.2 son considerados de efecto bajo; los cercanos a 0.5 de efecto mediano; y los cercanos o superiores a 0.8 , de efecto elevado.

Figura 3. Evolución semanal de las puntuaciones medias dadas por las jugadoras del GE a la comunicación del entrenador

Valoración de las jugadoras (Grupo Experimental)

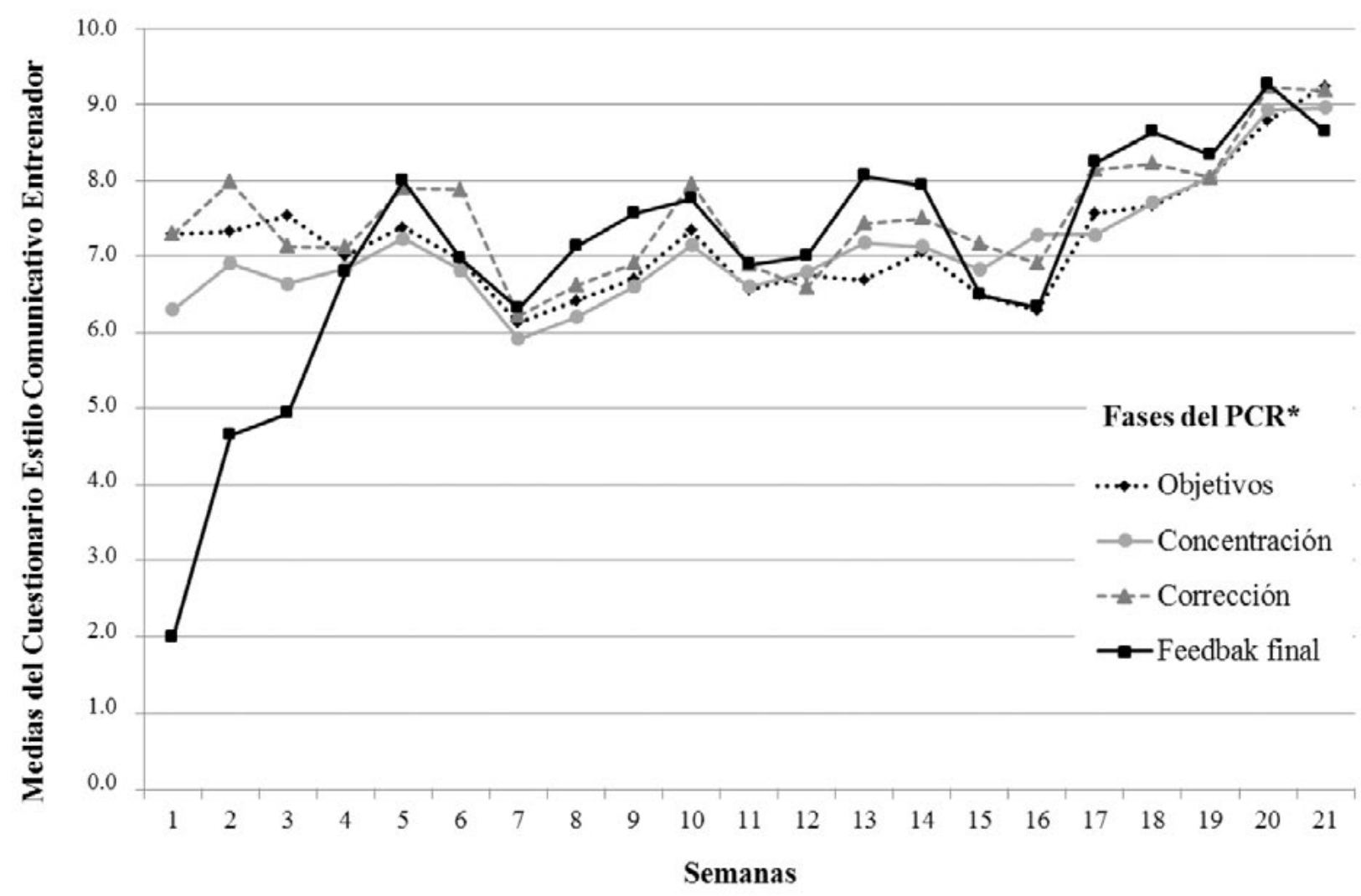

* PCR: Patrón Comunicativo Replicable del modelo La Cadena de la Conciencia 
Figura 4. Evolución semanal de las puntuaciones medias dadas por el entrenador del GE al seguimiento de las indicaciones comunicativas Valoración del entrenador (Grupo Experimental)

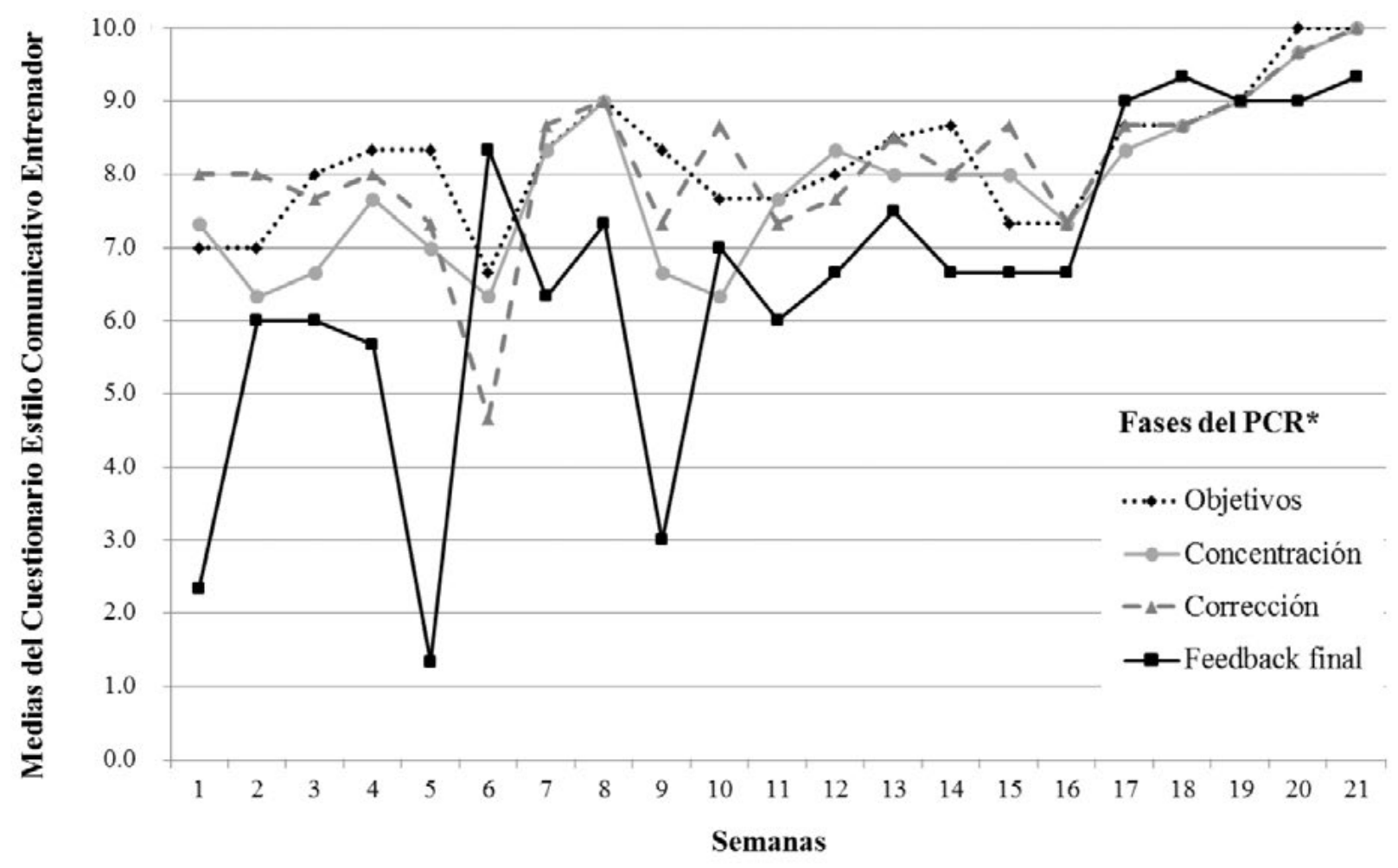

* PCR: Patrón Comunicativo Replicable del modelo La Cadena de la Conciencia

Tabla 2. Seguimiento (en porcentaje) de las indicaciones comunicativas valoradas por el entrenador del GE

\begin{tabular}{|c|c|c|c|}
\hline \multirow{2}{*}{ Fases del PCR } & \multirow{2}{*}{$\begin{array}{l}\text { Indicaciones comunicativas } \\
\text { valoradas por el entrenador del GE }\end{array}$} & \multicolumn{2}{|c|}{ \% sobre puntuación máxima } \\
\hline & & Por indicación & Por fase \\
\hline \multirow{4}{*}{$\begin{array}{l}\text { Planteamiento del } \\
\text { objetivo }\end{array}$} & Planteo qué queremos conseguir (no sólo qué hacer) & 99.19 & \multirow{4}{*}{86.29} \\
\hline & Especifico el objetivo; lo describo & 95.97 & \\
\hline & Lo formulo en positivo & 94.35 & \\
\hline & Identifico evidencias para saber cuándo el objetivo se consigue & 55.65 & \\
\hline \multirow{4}{*}{$\begin{array}{l}\text { Instrucciones so- } \\
\text { bre concentración }\end{array}$} & Instrucciones claras y en positivo & 100.00 & \multirow{4}{*}{81.85} \\
\hline & Relacionadas con el objetivo & 100.00 & \\
\hline & Oriento la concentración hacia lo que se debe leer tácticamente o qué debe notar técnicamente & 67.74 & \\
\hline & Hago uso de palabras clave o sensaciones conectadas con la acción o la concentración & 59.68 & \\
\hline \multirow{6}{*}{ Correcciones } & Corrijo en relación al objetivo (evitando dispersar el deportista) & 98.39 & \multirow{6}{*}{82.58} \\
\hline & Incido en el que hay que hacer bien (más que en lo que se hace mal) & 96.77 & \\
\hline & Refuerzo las cosas que se hacen bien & 95.16 & \\
\hline & Pregunto para hacer descubrir. Promuevo la auto-corrección & 95.16 & \\
\hline & $\begin{array}{l}\text { Hago hacer los gestos (o los movimientos) para identificar el momento clave donde hacer la } \\
\text { corrección }\end{array}$ & 66.13 & \\
\hline & Uso palabras clave asociadas al gesto, movimiento o acción & 57.26 & \\
\hline \multirow{4}{*}{ Feedback final } & Al final del ejercicio, hago una pequeña reunión para hablar de cómo ha ido & 83.06 & \multirow{4}{*}{66.39} \\
\hline & Hago participar los deportistas & 84.68 & \\
\hline & Hago valorar el logro del objetivo (poniendo notas) y buscamos acordar criterios & 51.61 & \\
\hline & Busco generar conciencia de cómo han sido capaces de hacerlo. Que se queden con una idea clara & 44.35 & \\
\hline
\end{tabular}


En la evolución percibida por el entrenador (Figura 4), la fase Feedback final también es la más inconsistente, y no es hasta la semana 17 que se estabiliza respecto a las demás.

El entrenador del GE, aparte de valorar globalmente el seguimiento realizado de cada fase del PCR, también valoró al final de cada entrenamiento el seguimiento de cada una de las indicaciones comunicativas, registrando si había seguido cada indicación, si lo había hecho a veces, o no la había seguido. En la Tabla 2 se muestra el porcentaje de seguimiento para cada indicación comunicativa en relación con la puntuación máxima posible.

Las puntuaciones globales por fase muestran que la fase de Feedback final es claramente la menos valorada (porcentaje de 66.39) en relación con el porcentaje máximo. En cuanto a las indicaciones comunicativas, para el Planteamiento del objetivo, la indicación menos puntuada fue "Identifico evidencias para saber cuándo el objetivo se cumple" (55.65); en la fase Instrucciones para guiar la concentración, la menos puntuada fue "Hago uso de palabras clave o sensaciones conectadas con la acción o la concentración" (59.68); para las Correcciones fue "Uso palabras clave asociadas al gesto, movimiento o acción a corregir" (57.26); y para el Feedback final, "Busco generar conciencia de cómo han sido capaces de hacerlo; que se queden con una idea clara" (44.35), en este caso, la menos puntuada de todas.

\section{Orientación motivacional}

En la orientación motivacional (Figura 5), los datos recogidos antes de la intervención revelan que hay una más alta orientación motivacional a la tarea en ambos grupos, y menor orientación al ego.

Después de la intervención, se observa un incremento de la orientación a la tarea y un decremento en la orientación al ego, en ambos grupos. Las diferencias entre antes y después son significativas para ambos grupos (Wilcoxon $p<.05$ ) y ambas orientaciones motivacionales (Tabla 3), si bien son más acusadas en el GE. Es al calcular la magnitud del efecto ( $d$ de Cohen) cuando encontramos grandes diferencias entre GE y GC. La magnitud en los cambios pre-pos del GE son moderados ( $d$ entre .5 y .8 , en valores absolutos) en el incremento de la orientación a la tarea (-.56) y el decremento de la orientación al ego (.55). Por contra, los cambios en el GC son de casi nula magnitud $(d<.2)$ en la orientación a la tarea (-.14) y de leve magnitud ( $d$ entre .2 y .5) en la orientación al ego ( .32).

Figura 5. Diferencias y magnitud de efecto (d) pre-pos intervención en relación con la orientación motivacional

\section{Orientación motivacional}

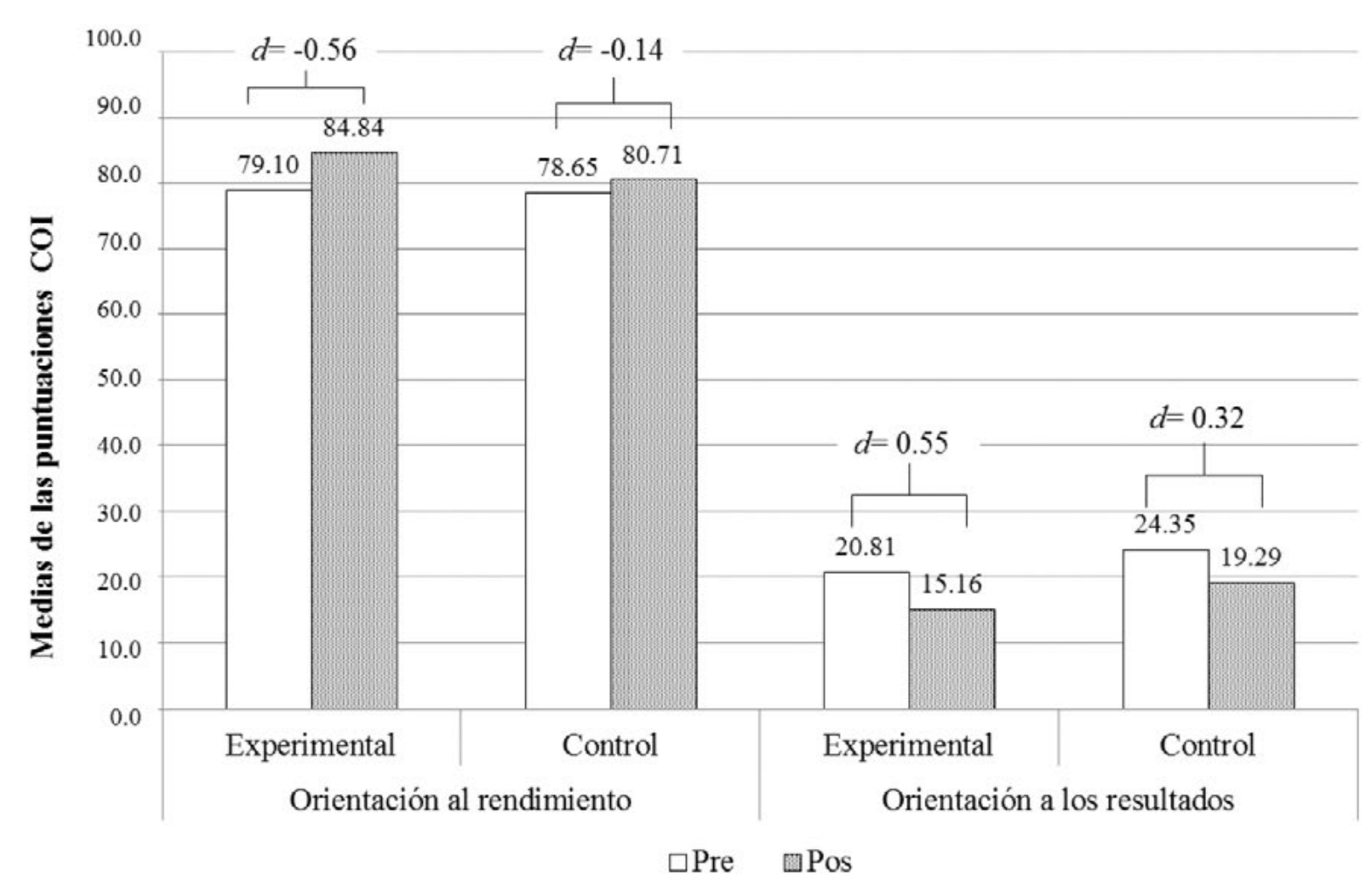

Nota: los valores $d$ negativos significan magnitud de efecto positivo. En términos absolutos, valores cercanos a 0.2 son considerados como efecto bajo; los cercanos a 0.5 como efectos mediano; y los cercanos o superiores a 0.8 , como efectos elevados. 


\begin{tabular}{llcccc}
\hline Tabla 3. Significación (Wilcoxon) de las diferencias pos-pre en la Orientación motivacional y la Confianza \\
\hline Diferencias pos-pre intervención & \multicolumn{2}{c}{ Orientación a tarea } & \multicolumn{2}{c}{ Orientacióna al ego } & Confianza \\
\cline { 2 - 6 } & $Z$ & $p$ & $Z$ & $p$ & Z \\
\hline Grupo experimental & -2.595 & .010 & -2.521 & .012 & -2.670 \\
\hline Grupo control & -2.751 & .006 & -2.803 & .005 & -1.826 \\
\hline
\end{tabular}

Z: Wilcoxon pos-pre; p: Significación $(p<.05)$.

\section{Confianza}

En la evaluación posterior a la intervención, se observa un incremento en los niveles de confianza, especialmente en el GE (Figura 6). Las diferencias son significativas para ambos grupos (Tabla 3), pero mientras que en el GE la magnitud de efecto es muy elevada (-2.52), en el GC la magnitud de efecto en los cambios observados es leve (-.23).

\section{Discusión y Conclusiones}

Con el fin de contrastar los efectos de la aplicación de las indicaciones propuestas por el modelo CC sobre la orientación motivacional y la confianza de los deportistas, se ha diseñado un estudio cuasiexperimental en el que el entrenador del GE ha aplicado las indicaciones del modelo durante 21 semanas, y se han comparado las diferencias entre estilos comunicativos de los entrenadores y las variables psicológi-

Figura 6. Diferencias y magnitud de efecto (d de Cohen) pre-pos intervención en relación con la confianza

\section{Confianza}

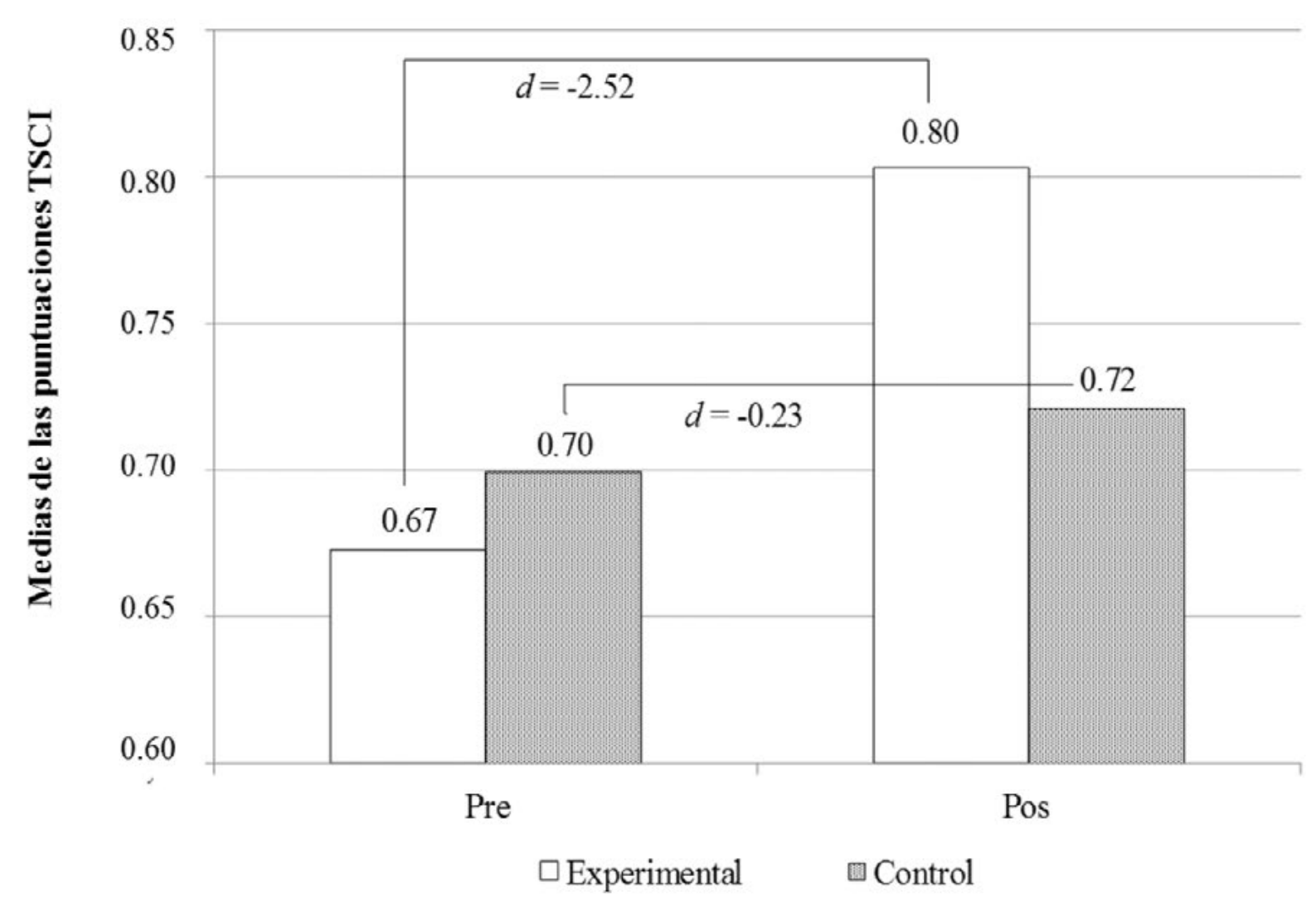

Nota: los valores $d$ negativos significan magnitud de efecto positivo. En términos absolutos, valores cercanos a 0.2 son considerados de efecto bajo; los cercanos a 0.5 de efecto mediano; y los cercanos o superiores a 0.8 , de efecto elevado. 
cas, entre GE y GC, antes y después de la intervención. Los resultados muestran cambios significativos pre-pos en la comunicación del entrenador del GE, para todas las fases comunicativas del PCR, y la magnitud de efecto correspondiente a tales cambios es elevada en las fases comunicativas donde más impacto tienen las indicaciones del modelo respecto a la conducta comunicativa habitual de los entrenadores (establecimiento de objetivos, instrucciones para la concentración, y feedback final). Los cambios pre-pos en la orientación motivacional responden a lo esperado, con incremento de orientación a la tarea y disminución de orientación al ego, sin diferencias significativas entre grupos, pero con una magnitud de efecto mayor en el GE. La confianza rasgo de las jugadoras del GE aumenta de forma significativa y con una magnitud de efecto elevada, en comparación con el GC.

Al ser éste el primer estudio que utiliza el modelo CC como procedimiento de intervención, la comparación con otros trabajos se realiza en base a similitudes en la concepción teórica de los modelos utilizados y los objetivos perseguidos. Los cambios comunicativos observados en el entrenador del GE indican una mejora a la hora de plantear los objetivos, vincular las instrucciones con la concentración, y aprovechar la evaluación de los objetivos para generar conciencia acerca de lo trabajado en los entrenamientos. En Cruz et al. (2016), Sousa et al. (2006) y Sousa et al. (2008), tras realizar intervenciones personalizadas con entrenadores, hay cierta coincidencia entre ellos al describir cambios comunicativos del entrenador relacionados con incremento de instrucción técnica, más refuerzo y menos punición. Vemos pues cierta relación con estos estudios en el hecho que las intervenciones realizadas (CC / PAPE) consiguen cambios comunicativos algo diferentes pero que inciden en las necesidades psicológicas de competencia (más conciencia sobre lo aprendido / más refuerzo,), autonomía (más participación del deportista / menos control por parte del entrenador) y relación (más ayuda técnica del entrenador / menos punición).

En cuanto a los efectos sobre la motivación, la tendencia observada tras intervenir sobre la conducta comunicativa del entrenador (más orientación a la tarea y menos al ego) son coincidentes con Álvarez et al. (2013). El hecho que ambos grupos muestren esta tendencia, si bien tiene una magnitud de efecto mayor en el GE, podría explicarse por la orientación y los valores de los entrenadores, en línea con el enfoque formativo del club (más que hacia el rendimiento). En lo que respecta a la confianza, los resultados coinciden con Forlenza et al. (2018), que demuestran cómo la influencia del entrenador y el clima generado por este son conductas que permiten desarrollar la confianza en los deportistas. En Reigal et al. (2018) también se vincula el clima de apoyo a la autonomía y el clima orientado a la tarea con la autoconfianza. Finalmente, el supuesto efecto cadena del modelo CC coincide en parte con lo que plantea el modelo de Pineda-Espejel et al. (2020), que confirman que el estilo de apoyo a la autonomía por parte del entrenador, la necesidad de competencia, la motivación autónoma, y finalmente la autoconfianza, se predicen de forma consecutiva.

Las diferencias entre los cambios observados en la orientación motivacional y la confianza en el GE pueden estar vinculadas con los cambios comunicativos positivos observados en el entrenador, a raíz de la intervención aplicada. El planteamiento metodológico de la intervención, pues, parece haber sido suficiente y compatible con lo que Sousa et al. (2015) y Pulido et al. (2019) indican, sobre la necesidad de conceder tiempo suficiente a la supervisión posterior a la formación, para conseguir cambios reales en la comunicación del entrenador.

En cuanto a limitaciones y/o aspectos a mejorar en el planteamiento del estudio, se debe identificar el hecho que grupo experimental y control son de género diferente (aunque eso permitió que fueran del mismo deporte, club, edad y nivel competitivo). Por lo que respecta a la etapa formativa en la intervención con el entrenador, ésta podría haber sido más extensa, si se toman como referencia las seis horas que el programa Empowering Coaching ${ }^{\mathrm{TM}}$ (Duda, 2013) dedica a este aspecto. También podrían haberse planteado ciclos para trabajar cada fase comunicativa por separado, tal como Harwood (2008) plantea para cada una de sus 5C. Finalmente, podría considerarse la incorporación de soporte audiovisual y documental en la etapa formativa, tal como proponen Cruz et al. (2016), Sousa et al. (2006) y Sousa et al. (2008).

Por lo que respecta al diseño del estudio y la evaluación, otro aspecto mejorable, que sí muestran estos mismos trabajos liderados por Cruz y Sousa, es el establecimiento de una línea base inicial acerca de las conductas objetivo, para ayudar al entrenador a comprender mejor la necesidad de cambiar e involucrarle en el planteamiento de objetivos, y poder hacer una evaluación comparativa después de la intervención. Este es un aspecto claramente identificativo de los PAPE (Rodríguez et al., 2017). En nuestro caso, como evaluación de la comunicación pre-pos, realizada a jugadores y entrenadores, utilizamos el cuestionario creado ad hoc, en base al seguimiento de las indicaciones que plantea el modelo CC. Si bien este instrumento no está aún validado, la validez de contenido de cada indicación está fundamentada en Vives-Ribó y Rabassa (2020). Y en lugar de establecer una línea base, se optó por una evaluación a través de registros de jugadoras y entrenador del GE, por lo tanto de nuevo con doble perspectiva, después de cada entrenamiento, a lo 
largo de las 21 semanas, aspecto que permitió identificar de forma precisa la evolución longitudinal en relación al seguimiento de las pautas del modelo.

Los estudios anteriormente mencionados usan observadores externos entrenados para realizar la observación y el registro con el CBAS. Esto asegura una coherencia en el criterio de evaluación, por lo que algo a considerar para futuros trabajos en que los jugadores deban registrar, sería hacerles participar en la etapa formativa, para asegurar así una correcta concepción de las indicaciones comunicativas a registrar.

Otras consideraciones sobre la evaluación, es que, en este estudio, para evaluar la orientación motivacional, se optó por utilizar el COI (Vealey, 1986) al estar conceptualmente relacionado con la otra variable (confianza), ofrecer un procedimiento de respuesta sin ítems (y, por lo tanto, sin necesidad de traducir ítems al español), y por referirse a vivencias habituales en competición. Esta elección quizás pueda condicionar la comparación con otros trabajos que optan por el más frecuentemente usado Cuestionario de Orientación al Ego y a la Tarea en el Deporte (TEOSQ), como por ejemplo en Álvarez et al. (2013). Es un aspecto a valorar para futuros trabajos. Para evaluar la confianza rasgo, se optó por la medida unidimensional en base al modelo original de Vealey (1986), el TSCI en su versión española (Herrera-Velásquez y Gómez-Maquet, 2020), aunque el modelo de Vealey evolucionó porteriormente hacia una concepción multidimensional. Pero tal como Machida et al. (2017) indican, la multidimensionalidad y su medición no han sido aun ampliamente estudiadas.

Finalmente, otra limitación en este estudio ha sido no contar con la medida de satisfacción del entrenador por la intervención realizada, tal como contemplan Cruz et al. (2016), Sousa et al. (2006) y Sousa et al. (2008). Esta evaluación puede complementar los resultados conseguidos, especialmente en la práctica aplicada, cuando pueden no darse las condiciones idóneas para realizar la evaluación de las variables psicológicas implicadas en la intervención (Vives-Ribó y Rabassa, 2020).

Como propuestas para investigaciones futuras, podría ser interesante el estudio de las necesidades psicológicas (autonomía, competencia y relación) como variables mediadoras entre los cambios comunicativos que la CC propone y los efectos psicológicos en los deportistas. También podría estudiarse si los cambios comunicativos que propone el modelo influyen directamente en las variables orientación motivacional y confianza, o si bien alguna de ellas predice a la otra, como muestran los resultados de Reigal et al. (2018). Otro aspecto a considerar es el estudio de los cambios en el clima motivacional después de intervenir con el entrena- dor, tal como plantean Álvarez et al. (2013) y Rodríguez et al. (2017). Finalmente, y de forma destacada, también quedaría por dilucidar qué papel juega la variable conciencia (aprendizaje consciente) en los cambios que pueda haber en la confianza de los deportistas. Aunque hay autores que han trabajado sobre el aprendizaje explícito, denominado así por la intención explícita acerca del propio acto de aprender y por el tratamiento explícito de la información relativa al objetivo de aprendizaje (e.g., Latinjak, 2014), el estudio de la conciencia en los aprendizajes, la influencia de la comunicación del entrenador en ella, y sus efectos sobre la motivación y la confianza son tópicos aún por desarrollar.

\section{Aplicaciones prácticas}

El modelo de la CC (Vives, 2011) es fruto de 14 años de experiencia aplicada, dedicada especialmente al trabajo con entrenadores. El recurso instrumental en el que se basa el modelo CC es la comunicación del entrenador, y por ello, la aplicabilidad de este modelo estará mayormente relacionada con este aspecto. La intervención expuesta en este trabajo, realizada en el entrenador del GE, permite inferir que el seguimiento continuado de las indicaciones comunicativas del modelo provoca cambios en la comunicación del entrenador, que pueden ser compatibles con un clima motivacional orientado a la tarea y un estilo de liderazgo definido por conductas de apoyo a la autonomía y a la competencia, relaciones que deberán ser contrastadas en futuros trabajos. El uso del modelo CC, pues, podría estar indicado en situaciones en las que, de forma primaria o secundaria, se busquen cambios en la comunicación, el clima motivacional y el estilo de liderazgo del entrenador, como objetivos de intervención.

El constructo diferencial por el que se distingue el modelo CC es la conciencia en los aprendizajes. Mientras la comunicación es el instrumento que utiliza el entrenador para influir en ella, el recurso necesariamente implicado para conseguir o incrementar la conciencia en los aprendizajes es la concentración de los deportistas. Las indicaciones comunicativas del modelo pueden ayudar a los entrenadores a orientar la concentración de los deportistas hacia los estímulos relevantes de la tarea. Esto de por sí, puede conllevar mejoras en los procedimientos didácticos utilizados por el entrenador $y$, en consecuencia, ser útil ante problemas o necesidades de mejora en el aprendizaje o en el rendimiento, relacionados con el déficit o la mala orientación de la concentración.

Finalmente, los resultados presentados en este artículo permiten corroborar la aplicabilidad del modelo en las situaciones relacionadas con la orientación motivacional y la con- 
fianza de los deportistas. Son comunes las situaciones en las que se necesita reorientar la motivación de los deportistas hacia la tarea, por ejemplo, cuando aparecen problemas en el aprendizaje o en el rendimiento por el miedo a fallar, o bien por la presión competitiva. Cuando los deportistas buscan seguridad en las expectativas de resultado, su confianza está mal orientada y a expensas de la actuación deportiva, pudiendo provocar déficits puntuales o inestabilidad en la autoconfianza o autoeficacia, influyendo negativamente en la consistencia a la hora de rendir. La aplicación del modelo CC será adecuada también en aquellas situaciones en las que se plantee construir, incrementar o recuperar los niveles de confianza, al basar ésta en las creencias acerca de las destrezas adquiridas en los entrenamientos ("sé que puedo porqué sé cómo"), en lugar de hacerlo sobre las expectativas de resultado deportivo.

Se ha podido comprobar, por tanto, la utilidad del modelo CC como herramienta para la intervención indirecta, es decir, aquella que se realiza no sobre el destinatario final, sino sobre un agente que tiene ascendencia sobre él. En deportes colectivos, este tipo de intervención es muy conveniente, no solo por lo eficiente que representa trabajar con el entrenador en lugar de hacerlo con la plantilla entera de jugadores, sino porque los cambios propuestos se acaban implementando sin las fisuras que podrían existir en caso que el psicólogo trabajase solo con los jugadores.

\section{Referencias}

Alvarez, O., Falco, C., Estevan, I., Molina-García, J. y Castillo, I. (2013). Intervención psicológica en un equipo de gimnasia rítmica deportiva: Estudio de un caso. Revista de Psicología del Deporte, 22(2), 395-401

Almagro, J., Conde, C., Moreno, A. y Sáenz-López, P. (2009). Analysis and comparison of adolescent athletes' motivation: Basketball players vs. Football players. Revista de Psicología del Deporte, 18(3), 353-356.

Ames, C. (1992). Classrooms: Goals, structures, and student motivation. Journal of Educational Psychology, 84(3), 261-271. https//doi.org/10.1037/0022-0663.84.3.261

Balaguer, I., Castillo, I., Duda, J. y García-Merita, M. (2011). Asociaciones entre la percepción del clima motivacional creado por el entrenador, orientaciones disposicionales de meta, regulaciones motivacionales y vitalidad subjetiva en jóvenes jugadoras de tenis. Revista de Psicología del Deporte, 20(1), 133-148.

Castillo, I., Ramis, Y., Cruz, J. y Balaguer, I. (2015). Formación de entrenadores de fútbol base en el proyecto PAPA. Revista de Psicología del Deporte, 24(1), 131-138.

Cordo-Cabal, L., Gómez-López, M., Granero-Gallegos, A. y Sánchez-Alcaraz, B. J. (2019). Relación del clima motivacional generado por el entrenador y las causas del éxito en jugadores de deportes de equipo. Influencia del género, la edad y la ex- periencia deportiva. Journal of Sport and Health Research, 17(2), 139-150.

Cruz, J., Torregrossa, M., Sousa, C., Mora, A. y Viladrich, C. (2010). Efectos conductuales de programas personalizados de asesoramiento a entrenadores en estilo de comunicación y clima motivacional. Revista de Psicología del Deporte, 20(1), 179-195

Cruz, J., Mora, À., Sousa, C. y Alcaraz, S. (2016). Efectos de un programa personalizado sobre los comportamientos observados y percibidos de los entrenadores. Revista de Psicología del Deporte, 25(1), 137-144.

Deci, E. L. y Ryan, R. M. (2012). Self-Determination Theory. En P.A.M. Van Lange, A.W. Kruglanski y E.T. Higgins (Eds.), Handbook of theories of social psychology (pp. 349-373). Sage Publications.

Duda, J. L. (2013). The conceptual and empirical foundations of Empowering Coaching ${ }^{\mathrm{TM}}$ : Setting the stage for the PAPA project. International Journal of Sport and Exercise Psychology, 17(4), 1-8. https//doi.org/10.1080/1612197x.2013.839414

Forlenza, S. T., Pierce, S., Vealey, R. S. y Mackersie, J. (2018). Coaching behaviors that enhance confidence in athletes and teams. International Sport Coaching Journal, 5(3), 205-212. https//doi.org/10.1123/iscj.2017-0040

Fritz, C. O., Morris, P. E. y Richler, J. J. (2012). Effect size estimates: current use, calculations, and interpretation. Journal of experimental psychology: General, 141(1), 2. https://doi.apa.org/doi/10.1037/a0024338

Harwood, C. (2008). Developmental consulting in a professional football academy: The 5Cs coaching efficacy program. The sport psychologist, 22(1), 109-133. https://doi.org/10.1123/tsp.22.1.109

Herrera-Velásquez, D. A. y Gómez-Maquet, Y. (2020). Efecto de un programa de práctica imaginada sobre la autoconfianza de futbolistas. Pensamiento Psicológico, 18(2), 1-28. https://doi.org/10.11144/Javerianacali.PPSI18-2.eppi

Latinjak, A. T. (2014). Aprendizaje implícito y explícito: entre el hacer y el comprender. En V. López-Ros y J. Sargatal (Eds.), El aprendizaje de la acción táctica (pp. 59-85). Universitat de Girona.

Machida, M., Ward, R. M. y Vealey, R. S. (2012). Predictors of sources of self-confidence in collegiate athletes. International Journal of Sport and Exercise Psychology, 10(3), 172-185. https//doi.org/10.1080/1612197X.2012.672013

Machida, M., Otten, M., Magyar, T. M., Vealey, R. S. y Ward, R. M. (2017). Examining multidimensional sport-confidence in athletes and non-athlete sport performers. Journal of sports sciences, 35(5), 410-418. https//doi.org/10.1080/02640414.2016.11 67934

Morgan, K. (2017). Reconceptualizing motivational climate in physical education and sport coaching: An interdisciplinary perspective. Quest, 69(1), 95-112. https://doi.org/10.1080/0033629 7.2016.1152984

Peris, D. y Cantón, E. (2018). El perfil profesional del especialista en psicología del deporte en fútbol. Revista de Psicología Aplicada al Deporte y al Ejercicio Físico, 3(1), Artículo e9. https://doi.org/10.5093/rpadef2018a6

Pineda-Espejel, H.A., Morquecho-Sánchez, R. y Alarcón, E. (2020). Estilo interpersonal del entrenador, competencia, motivación, y ansiedad precompetitiva en deportistas de alto rendimiento. Cuadernos de Psicología del Deporte, 20(1), 10-24. https://doi.org/10.6018/cpd.397001 
Pulido, J. J., Merino, A., Sánchez-Oliva, D., Tapia, M. A. y García-Calvo, T. (2019). Efectos de un programa de intervención sobre el estilo interpersonal de entrenadores de fútbol base. Cuadernos de Psicología del Deporte, 19(1), 32-49. https://doi.org/10.6018/ cpd.334231

Reigal, R.E., Crespillo, M., Morillo, J.P. y Hernández-Mendo, A. (2018). Apoyo a la autonomía, clima motivacional percibido y perfil psicológico deportivo en jugadores de balonmano playa. Cuadernos de Psicología del Deporte, 18(3), 102-111.

Rodríguez, M.P., Cruz, J. y Torregrossa, M. (2017). Programa de intervención con entrenadores y padres de familia: Efectos en las conductas del entrenador y el clima motivacional del equipo. Revista de Psicología del Deporte, 26(2), 181-187

Smith, R. E., Smoll, F. L. y Cumming, S. P. (2007). Effects of a motivational climate intervention for coaches on children's sport performance anxiety. Journal of Sport and Exercise Psychology, 29, 39-59. https://doi.org/10.1123/jsep.29.1.39

Smith, R. E., Smoll, F. L. y Cumming, S. P. (2009). Motivational climate and changes in young athletes' achievement goal orientations. Motivation and Emotion, 33(2), 173-183. https://doi.org/10.1007/s17031-009-9126-4

Smith, R. E. y Smoll, F. L. (2017). Coaching behavior and effectiveness in sport and exercise psychology. Oxford Research Encyclopedia of Psychology (online publication). https://doi.org/10.1093/acrefore/9780190236557.013.188

Sousa, C., Cruz, J., Torregrosa, M., Vilches, D. y Viladrich, C. (2006). Evaluación conductual y programa de asesoramiento personalizado a entrenadores (PAPE) de deportistas jóvenes. Revista de Psicología del Deporte, 15(2), 263-278.
Sousa, C., Smith, R. E. y Cruz, J. (2008). An individualized behavioral goal-setting program for coaches: Impact on observed, athlete-perceived, and coach-perceived behaviors. Journal of Clinical Sport Psychology, 2, 258-277. https://doi.org/10.1123/ jcsp.2.3.258

Sousa, C., Cruz, J. y Smith, R. E. (2015). Evaluación y asesoramiento a entrenadores: intervenciones en el contexto. En J. M. López Walle, M. P. Rodríguez, O. Ceballos y J. L. Tristán (Eds.), Psicología del deporte: conceptos, aplicaciones e investigación (pp. 149-165). Universidad Autónoma de Nuevo León.

Torregrosa, M., Sousa, C., Viladrich, C., Villamarín, F. y Cruz, J. (2008). El clima motivacional y el estilo de comunicación del entrenador como predictores del compromiso en futbolistas jóvenes. Psicothema, 20(2), 254-259.

Vealey, R. (1986). Conceptualization of Sport-Confidence and Competitive Orientation: Preliminary Investigation and Instrument Development. Journal of Sport Psychology, 8, 221- 246. https://doi.org/10.1123/isp.8.3.221

Villalonga, T., Garcia-Mas, A., de las Heras, R., Buceta, C. y Smith, R. E. (2015). Instauración y tareas de un servicio de psicología del deporte en un club de fútbol profesional. Revista de Psicología del Deporte, 24(2), 319-326.

Vives, J. (2011). Entrenando al entrenador. Ideas y trucos para una comunicación constructiva y eficaz (pp. 199-206). Editorial Bubok.

Vives-Ribó, J. y Rabassa, N. (2020). Intervención sobre la comunicación del entrenador para aumentar la confianza de los deportistas. Revista de Psicología Aplicada al Deporte y el Ejercicio Físico, 5(1), Artículo e6. https://doi.org/10.5093/rpadef2020a1 